BISSET, K. A. (1957). J. gen. Microbiol. 17, 562-566

\title{
Some Observations upon the Mode of Sporulation and Relationships of Monosporous Actinomycetes
}

\author{
By K. A. BISSET \\ Department of Bacteriology, University of Birmingham
}

SUMMARY: The modes of sporulation of Micromonospora chalcea, the parasitic Actinomyces odontolyticus and of stages in the primary mycelium of a strain of Streptomyces are compared. All produce spores singly on short side-branches, but the characters of the parasitic Actinomyces appear to be neotenic and degenerate, whereas those of the Streptomyces are primitive, and show signs of affiliations with a variety of different genera.

The classification of the actinomycetes given in Bergey's Manual (6th ed. 1948) is based upon that of Ørskov (1923), and although it is founded upon morphological considerations is notably defective in its information. This is especially true in regard to the parasitic microaerophiles, the true Actinomyces. The members of this genus possess a life-cycle of a comparable type to that of other actinomycetes (Morris, 1951; Prévot, 1953; Batty, 1957), but this has been overlooked by the earlier observers; Bergey's Manual (1948) simply states: 'No conidia produced'.

Although the mode of sporulation of Micromonospora is recorded in general terms: '. . conidia produced singly at the end of special conidiophores' (Bergey's Manual), the details have never been investigated. The best illustration available is that of Morris (1952). Micromonospora is assigned to the same family as Streptomyces, but the differences between them are very considerable.

The mode of sporulation of the parasitic Actinomyces is so remarkable, that it has appeared curious to me that it should be found only in that genus and in Micromonospora; both of which are, in their respective ways, rather highly specialized. And repeated attempts have been made in this laboratory to discover comparable bacterial forms of a more generalized type. In particular, it would be of great interest, in view of past confusion concerning the nature of parasitic Actinomyces, to determine their free-living counterparts.

In this paper a strain of Streptomyces is described which reproduces itself indefinitely in the primary phase upon routine bacteriological media, and without forming an aerial mycelium produces spore-like bodies in a variety of forms, the morphology of which is compared with that of the spores of Micromonospora and Actinomyces. It is concluded that it is a relatively primitive form, whereas the parasitic $A$. odontolyticus is degenerate.

\section{MATERIALS}

Three strains of Micromonospora chalcea were examined; these were isolated in this laboratory by Mr L. A. Davey from cultivated soil.

Six strains of Actinomyces odontolyticus were examined; these were isolated 
in this laboratory, from human saliva and carious teeth by Miss I. Batty, by whom it is described (Batty, 1957). It closely resembles $A$. bovis in its life-cycle, but was chosen for this study because it is considerably easier to grow in artificial culture, after the initial difficulties of isolation have been overcome.

The strain of Streptomyces was isolated from soil in the course of a class exercise. It grows slowly on most standard media, at temperatures below $\mathbf{3 2}^{\circ}$ (approx.), and is not exacting in respect of $\mathrm{pH}$ value, but, of those media examined, does not produce an aerial mycelium except on malt or oatmeal agar. The colonies on agar are grey and waxy, resembling those of Bacillus cereus. They are not adherent to the medium. When the aerial mycelium is formed it is abundant, pink and adherent.

\section{METHODS}

The Micromonospora strains were grown upon a medium consisting of $1 \%$ glucose, $0.05 \% \mathrm{~K}_{2} \mathrm{HPO}_{4}$ and $0.05 \%$ asparagine solidified with $1.5 \%$ agar in tap water, at $\mathrm{pH} 6 \cdot 8$, at a temperature of $15^{\circ}$ aerobically. The Actinomyces odontolyticus strains were grown on meat infusion agar with $10 \%$ horse blood at $\mathrm{pH} 7 \cdot 6$, at $37^{\circ}$, in a closed jar filled with as many inoculated plates as it would contain. This induced moist, slightly microaerophilic conditions suitable to the growth of this species, which is rather more resistant to oxygen than are newly isolated strains of $A$. bovis. Streptomyces was grown on meat infusion agar for cytological examination of the primary mycelium.

Smears were stained by the method of Hale (1953) for cell walls.

\section{RESULTS}

The spores of Micromonospora chalcea were produced at all stages of growth of the colony, after the first 2 or 3 days. They could be seen simultaneously in the same culture, either upon long or short stalks or in clusters (Pl. 1, figs. 1-8). Thus the suggestion that these characters may have a taxonomic value (Bergey's Manual, 6th ed., 1948) is obviously without foundation. Yet another type of spore arrangement was frequently found, which controverts the definition of the genus, since these spores were not at the ends, but at some distance from the ends of the sporogenous filaments, with a projecting portion of the filament beyond ( $\mathrm{Pl}$. 1, figs, 9, 10). The immature spores were lanceolate (Pl. 1, figs. 1, 4) but they became spherical when mature. There was no sign, at any stage of growth, of anything resembling an aerial mycelium.

The spores of Actinomyces odontolyticus were produced in cultures from 1 or 2 weeks old, singly or in small groups on small pieces of fragmented mycelium. The stalk was always very short, and the spore retained the lanceolate shape to maturity ( $\mathrm{Pl}$. 1, figs. 11-15). The resemblance between the immature spores of the Micromonospora and the mature spores of the Actinomyces was very close (Pl. 1, figs. 1, 4 and 13-15). The arrangement of the larger groups of spores, on short side-branches, was also exceedingly similar in both genera (Pl. 1, figs. 7, 11, 15 and tracings). This resemblance extends to the 
process of formation of the spores, so far as it can be deduced from the appearances described (see Discussion).

The initial growth of the Streptomyces consisted, as in Actinomyces (Morris, 1951; Batty, 1957), of short, bacillary forms, but these were soon replaced by longer septate filaments, sparingly branched, upon which the spores were formed, in a variety of arrangements. Some of these bore a marked resemblance to the spores of Micromonospora ( $\mathrm{Pl}$. 2, figs. 16-20), but were less regularly spherical. Some were oblong, and the younger stages oval or lanceolate. There were also large spores which had the appearance of acorns, and were borne at the angle of a sharply bent filament ( $\mathrm{Pl}$. 2, figs. 16, 17 and 19). These had a distinct sign of segmentation at the base, representing the cup of the acorn. Other spores were borne at the tips of short filaments, and again they were not always spherical, but frequently oval or oblong ( $\mathrm{Pl}$. 2, figs. 2124). This type of spore was also found to be segmented at the base in some instances (Pl. 2, figs. 23, 24). Occasionally a more complete segmented type of spore was seen, giving the appearance of a short chain (Pl. 2, figs. 25, 26).

In addition, a very characteristic appearance occurred quite commonly at all stages of culture. This took the form of pairs of oblong cells conjoined in a fashion exceedingly suggestive of conjugation (Pl. 2, figs 27-29), and especially reminiscent of the mode of formation of the 'initial cells' of the secondary mycelium in Actinomyces and Micromonospora described by Morris (1951, 1952), and in Streptomyces by Klieneberger-Nobel (1947) and Dickenson \& Macdonald (1955). It is conceivable that the 'acorn' spores may be arrested initial cells.

These various appearances were also observed in the early stages of growth on media upon which the entire life-cycle was completed, with the formation of long chains of aerial spores.

\section{DISCUSSION}

The appearance of the immature and maturing spores of Micromonospora chalcea and Actinomyces odontolyticus suggests that these develop in the same way, as enlargements upon an existing filament, and not by outgrowth from the tip. This is clearly seen in both cases by the lanceolate form of the immature spore, which carries its major enlargement at some distance from the pointed tip, and which is as long or longer than the mature form in many cases. It is even more clearly seen in those spores of $\boldsymbol{M}$. chalcea which are not produced at the end of the sporogenous filament but at some distance from it. Corresponding differences are seen in A. odontolyticus between spores with longer or blunter tips. The entire sporulation process in $A$. odontolyticus is suggestive of degeneracy and neoteny, as might reasonably be expected of a parasite. But the two processes resemble one another very closely, and may be presumed to indicate a relationship between these genera.

The arrest of the Streptomyces in the early stages of its life-cycle, presumably by reason of nutritional deficiency of substances present in malt and oatmeal, but absent in nutrient agar, offers an opportunity to study the curiously diverse modes of spore production in the pre-aerial mycelium. These spores 
Journal of General Microbiology, Vol. 17, No. 3

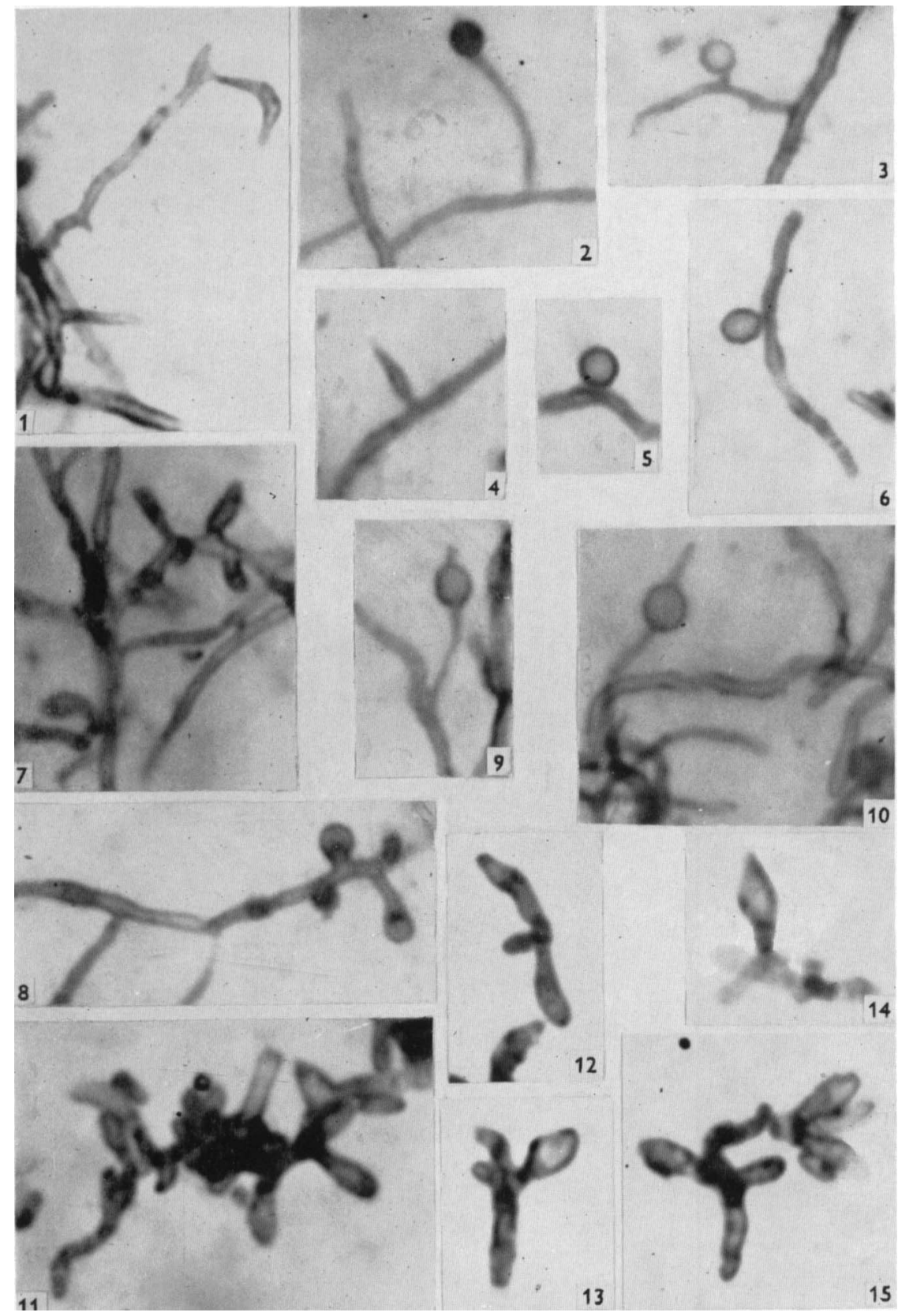

K. A. Bisset-Monosporous detholyogtes. Plate 1 
Journal of General Microbiology, Vol. 17, No. 3

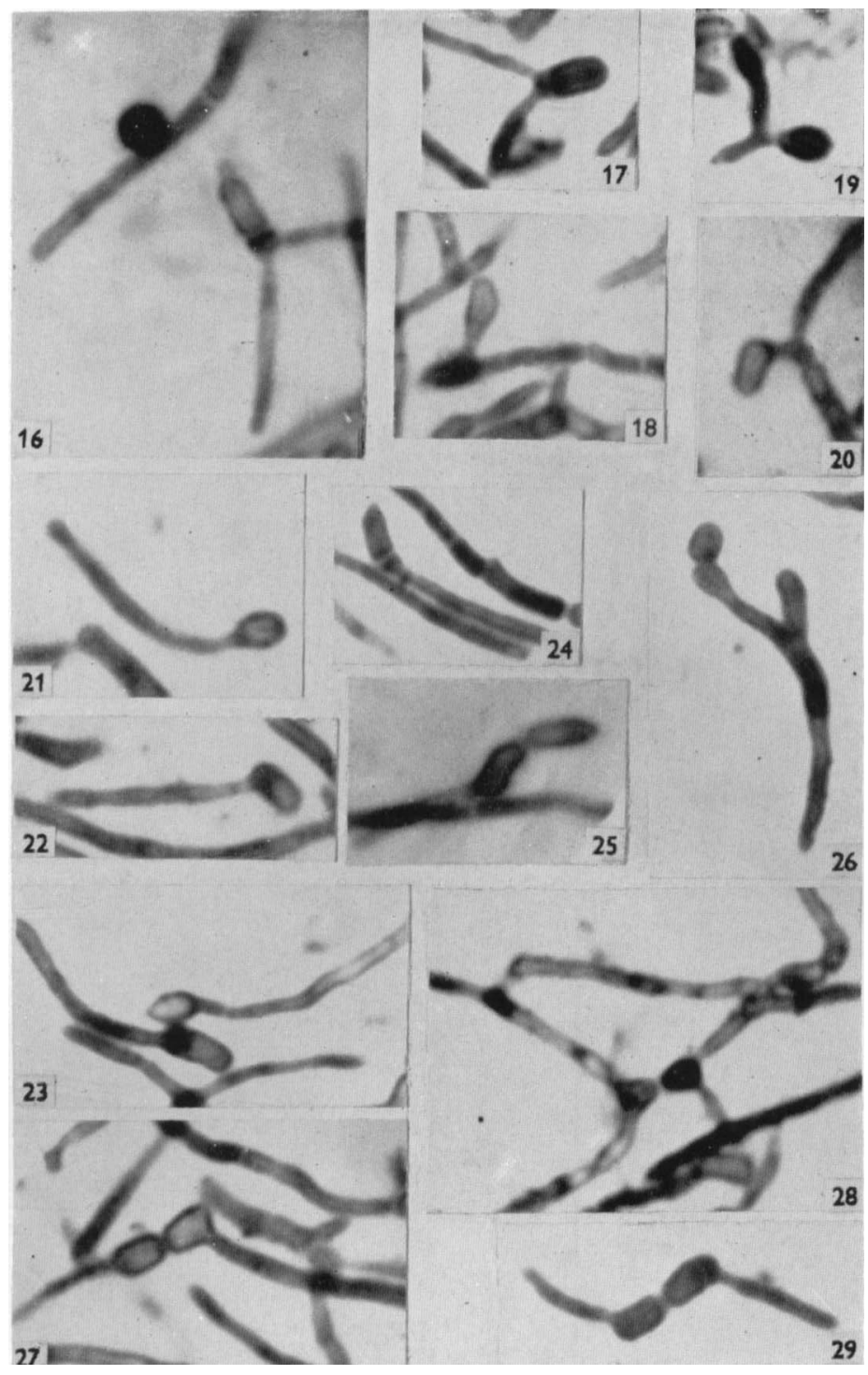

K. A. Bisset-Monosponous acthomfontes. Plate 2 
are simulacra of those of Micromonospora, when borne on side branches, or even of Nocardia, when borne on the main filaments (Pl. 2, figs. 21-23), or may be in short chains, more typical of Streptomyces itself, albeit incomplete. Thus this genus, although possessing a very complex life-cycle, proves to possess the potential of forming spores in different ways diagnostic of different genera of actinomycetes, and may thus be more primitive than the specialized Micromonospora and degenerate parasitic Actinomyces.

\section{REFERENCES}

BATTY, I. (1957). Species of Actinomyces regularly isolable from deep carious dentine. J. Path. Bact. (in the Press).

Bergey's Manual of Determinative Bacteriology (1948). 6th ed. Edited by Breed, R. S., Murray, E. G. D. \& Hitchens, A. P. London: Baillière, Tindall and Cox.

Dickenson, P. B. \& Macdonald, K. D. (1955). An electron microscope examination of the initial cell stage in Streptomyces spp. J. gen. Microbiol. 13, 84.

Hale, C. M. F. (1953). The use of phosphomolybdic acid in the mordanting of bacterial cell walls. Lab. Practice, 2, 115.

KLIENEBerger-Nobel, E. (1947). The life-cycle of sporing Actinomyces as revealed by a study of their structure and septation. J. gen. Microbiol. 1, 22.

Morris, E. O. (1951). The life-cycle of Actinomyces bovis. J. Hyg., Camb. 49, 46.

Morris, E. O. (1952). The cytology of the filamentous bacteria. Chem. \& Ind. p. 120.

Ørskov, J. (1923). Investigations into the morphology of Ray Fungi. Copenhagen: Levin and Munksgaard.

Prévot, A. R. (1953). Morphologie, physiologie, pouvoir pathogène et systématique des Actinomycétales anaérobies. Actinomycetales. Symp. 6th Congr. Int. Microbiol. Rome.

\section{EXPLANATION OF PLATES}

\section{Plate 1}

All figures are photomicrographs of preparations stained by Hale's method, at magnification $\times \mathbf{8 , 0 0 0}$.

Fig. 1. Micromonospora chalcea, immature spore on side-branch of long stalk.

Fig. 2. M. chalcea, mature spore on long stalk.

Fig. 3. $M$. chalcea, mature spore on side-branch.

Fig. 4. M. chalcea, immature spore on short stalk.

Figs. 5, 6. M. chalcea, mature spores on short stalks.

Fig. 7. M. chalcea, group of immature spores.

Fig. 8. M. chalcea, group of maturing spores.

Figs. 9, 10. M. chalcea, spores at various distances from the end of the filament.

Fig. 11. Actinomyces odontolyticus, group of maturing spores.

Fig. 12. $A$. odontolyticus, single immature spore.

Figs. 13-15. A. odontolyticus, mature and maturing spores.

\section{Plate 2}

Fig. 16. Streptomyces sp., mature spore and acorn like cell; the latter may represent an initial cell.

Fig. 17. Streptomyces sp. acorn cell.

Figs. 18-20. Streptomyces sp. spores on side-branches.

Figs. 21-24. Streptomyces sp. terminal spores; fig. 24, is immature.

Figs. 25, 26. Streptomyces sp. short chains of spores.

Figs. 27-29. Streptomyces sp. appearances interpreted as stages in initial cell formation. 

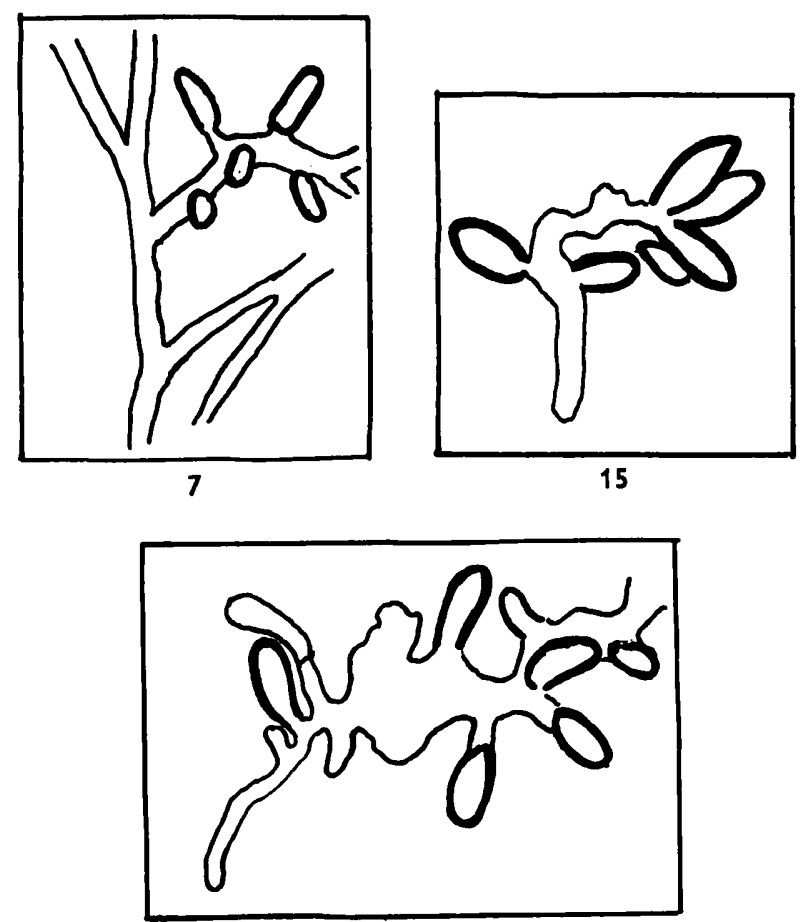

11

Tracings of Figs. 7, 11 and 15, showing groups of immature spores of Micromonospora chalcea compared with groups of maturing and mature spores of Actinomyces odontolyticus.

(Received 5 March 1957) 